Saber Humano, ISSN 2446-6298, V. 8, n. 12, p. 143-167, jan./jul. 2018.

\title{
Processo da estratégia empresarial e o líder de ação
}

\author{
Dinara Simone Pozzatti ${ }^{1}$ \\ Patrícia Wazlawick ${ }^{2}$
}

\begin{abstract}
Resumo: O propósito deste artigo é compreender como se dá o processo da estratégia empresarial, pelos principais gestores, para garantir o resultado estratégico da empresa. A pesquisa qualitativa com característica exploratória aborda a prática, a eficiência e o método aplicado para manter a empresa com desempenho superior, além de evidenciar o líder como centro operativo. $\mathrm{O}$ estudo avança e contribui para que outros gestores possam incrementar em suas empresas essa relação do líder ao escopo da empresa como ponto força. Os dados foram coletados mediante entrevistas pessoais, em profundidade com os Gerentes de uma grande empresa de calçados do Rio Grande do Sul, sendo 5 Gestores de referência para o desenvolvimento e acompanhamento do Planejamento Estratégico da empresa. Dentre os resultados obtidos, destacam-se: o programa desenvolvido pela empresa como unidade de ação; funções bem definidas; qualidade e bons equipamentos; satisfação do cliente em primeiro lugar. $\mathrm{O}$ resultado acontece porque cada gestor acompanha e avalia diariamente os processos, tendo sempre a informação em tempo real, e também porque a empresa tem uma configuração organizacional bem estruturada.
\end{abstract}

Palavras chaves: Estratégia empresarial. Resultado estratégico. O líder. Desempenho superior. Implementação da Estratégia.

\section{Process of the business strategy and the leader of action}

\begin{abstract}
The purpose of this work is to understand how the process of business strategy is given by the main managers to guarantee the strategic result of the company. The qualitative research with an exploratory characteristic addresses the practice, the efficiency and the method applied to maintain the company with superior performance, besides evidencing the leader as an operational center. The study advances and contributes so that other managers can increase in their companies this relation of the leader to the scope of the company as strength point. The data were collected through personal interviews, in-depth with the Managers of a large footwear company in Rio Grande do Sul, 5 of which were managers for the development and follow-up of the company's Strategic Planning. Among the obtained results stands out: the program developed by the company as a unit of action "Conquering Perfection"; well-defined functions; quality, good equipment; customer satisfaction first. The result is that each manager monitors and evaluates the processes on a daily basis, always having the information in real time and the company a well structured organizational configuration.
\end{abstract}

Keywords: Business strategy. Strategic Outcome. The leader. Superior performance. Managers. Implementation of the Strategy

\section{Procedimiento de la estrategia empresarial y el líder de acción}

\footnotetext{
${ }^{1}$ Bacharel em Ciências Contábeis pelo Centro de Ensino Superior de Maringá (CESUMAR). MBA em Identidade Empresarial pela Faculdade Antônio Meneghetti (AMF).

${ }^{2}$ Possui Doutorado em Psicologia pela Universidade Federal de Santa Catarina (UFSC), na Linha de Pesquisa Constituição do Sujeito, Relações Estéticas e Processos de Criação. Mestrado em Psicologia pela Universidade Federais do Paraná (UFPR. Especialista em Psicologia com abordagem em Ontopsicologia pela Saint-Petersburg State University (Universidade Estatal de São Petersburgo, SPbU), na Rússia. Especialista em Gestão do Conhecimento e o Paradigma Ontopsicológico (AMF, 2011-2014).
} 
Saber Humano, ISSN 2446-6298, V. 8, n. 12, p. 143-167, jan./jul. 2018.

\begin{abstract}
Resumen: El propósito de este artículo es comprender cómo se da el proceso de la estrategia empresarial por los principales gestores para garantizar el resultado estratégico de la empresa. La investigación cualitativa con característica exploratoria aborda la práctica, la eficiencia y el método aplicado para mantener la empresa con desempeño superior, además de evidenciar al líder como centro operativo. El estudio avanza y contribuye a que otros gestores puedan incrementar en sus empresas esa relación del líder al alcance de la empresa como punto de fuerza. Los datos fueron colectados mediante entrevistas personales, en profundidad con los Gerentes de una gran empresa de calzados de Rio Grande do Sul, siendo 5 Gestores de referencia para el desarrollo y seguimiento de la Planificación Estratégica de la empresa. Entre los resultados obtenidos se destaca: el programa desarrollado por la empresa como unidad de acción; funciones bien definidas; calidad y buenos equipos; satisfacción del cliente en primer lugar. El resultado es que cada gestor acompaña y evalúa diariamente los procesos teniendo siempre la información en tiempo real y la empresa tiene una configuración organizacional bien estructurada.

Palabras claves: Estrategia empresarial. Resultado estratégico. El líder. Rendimiento superior. Aplicación de la Estrategia.
\end{abstract}

\title{
1 Introdução
}

Este artigo tem como tema: o processo da estratégia e o líder de ação no dia a dia da gestão. O estudo foi realizado em uma empresa de calçados do Rio Grande do Sul, tendo como questões norteadoras contextualizar a prática, a eficiência e o método aplicado, demonstrando a operacionalização dos setores quanto às metas e resultados esperados pela empresa.

A presente pesquisa propõe um aprofundamento da análise do papel destes atores no processo de alinhamento. Nesse sentido, observa-se clara lacuna da literatura nas descrições das práticas configuradas em eventos organizacionais rotineiros.

Este artigo vem acarear o que Andrews (2006, p.79-80) argumenta: "a estratégia corporativa é um processo organizacional, de muitas formas inseparáveis da estrutura, do comportamento e da cultura da empresa onde ocorre", que a formação da estratégia desenvolvese por um processo intelectual, com viés econômico, pela análise de risco entre capacidade da empresa e as oportunidades de mercado.

Portanto o problema de pesquisa é: Como se dá o processo da estratégia empresarial, pelos principais gestores para garantir o resultado estratégico? Nesse sentido, como a ideia (planejamento da empresa) toma vida, vira ação pelos gestores e faz o resultado? Assim, o objetivo geral do estudo é identificar como se dá o processo da estratégia empresarial, pelos principais gestores, para garantir o resultado estratégico. 
Este artigo apresenta os resultados de um estudo exploratório, sobre a gestão estratégica da indústria de calçados, sendo os objetivos específicos:

1 Identificar o plano de ação da gestão no dia a dia do trabalho por parte dos gestores;

2 Verificar como acontece o processo de incorporação das decisões dos gestores por parte dos liderados, para garantir o resultado do planejamento estratégico;

3 Analisar como estão sendo utilizadas a gestão do conhecimento e a inteligência competitiva da empresa.

O estudo traz uma perspectiva da estratégia centralizada na ação humana, ou em suas práticas, como uma atividade que se desenvolve no dia a dia, nos encontros sociais e formais, por pessoas que constroem e são construídas pelo contexto organizacional e institucional. Voltada para o planejamento estratégico a partir das pessoas, percebe-se que a influência do perfil de administradores e da capacidade organizacional no resultado do planejamento estratégico já havia sido identificada na proposta de abordagem da administração estratégica de Ansoff (1965).

$\mathrm{O}$ artigo relata como os entrevistados trabalham e desenvolvem suas atividades em um momento histórico em que outras empresas não obtêm o mesmo desempenho.

\section{Fundamentação teórica}

Para ser eficaz, o processo do planejamento estratégico não deve ser um processo simplesmente formal e burocratizado. Ele deve começar com algumas questões simples, como: como está a organização hoje? Como está seu desempenho diante dos clientes e da concorrência? Como estará em um ano? Ou dois, cinco, dez anos? Com quais decisões os gestores deverão se deparar? Quais são os riscos?

Com base nestes pontos e com as respostas obtidas chega-se aos objetivos, e, analisando exequibilidade, adequação e aceitação dos objetivos e reexaminando recursos e circunstâncias, chega-se à estratégia proposta. 


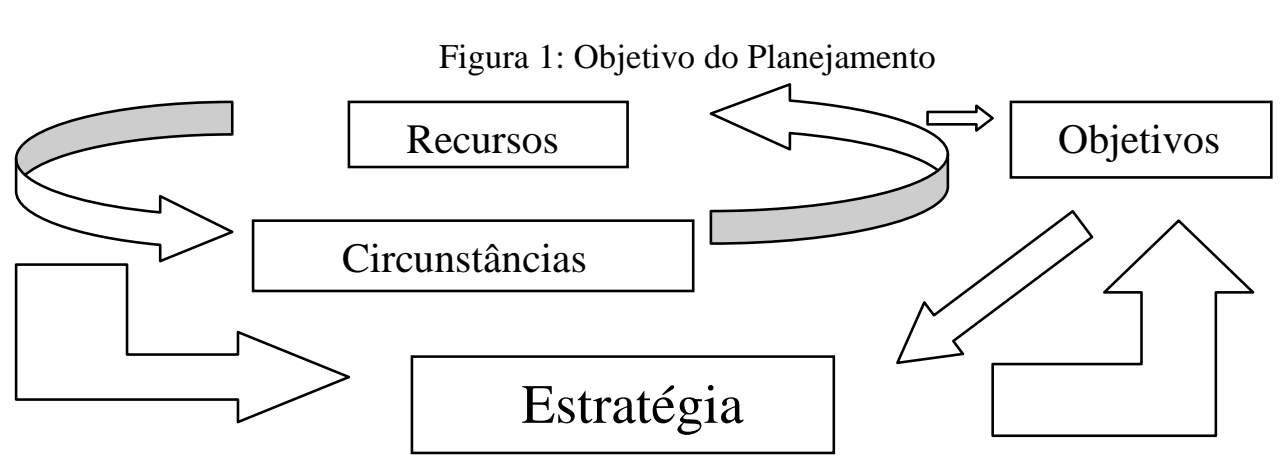

Fonte: Bethlem, Agrícola ( 2009).

Avaliar os recursos e circunstâncias significa conhecer a visão atual da empresa. O que a empresa será? O que a empresa fará? Como e onde a empresa estará? Este conjunto define o futuro, sendo essa a estratégia para chegar ao objetivo previamente definido e de acordo com os recursos e as circunstâncias já estudadas.

\subsection{Processo da estratégia e o líder de ação}

O planejamento estratégico clássico é um processo estruturado para fazer um bom plano e construir um futuro considerado possível e desejável para a empresa. Contudo, esse planejamento não incorporava os mecanismos gerenciais, administrativos e financeiros para sua implementação nem para levar em conta as constantes alterações necessárias para incorporar as surpresas estratégicas.

A gestão estratégica, reconhecendo esta grave lacuna, incorporou novos elementos ao planejamento estratégico, passando a considerar que o ambiente externo das empresas é cada vez mais dinâmico, cheio de ameaças e de oportunidades, o que significa que a construção do futuro precisa ser dinâmica e tratada gerencialmente como um projeto praticamente em tempo real.

Muito interessante o que Levy (1986) escreve acerca do pensamento estratégico como força e iniciativa, e não como teoria:

O pensamento estratégico é a parte não analítica do "ser empresário", é a iniciativa, o empreendedorismo, a força, a retomada, a imaginação. O criativo, que gera a fagulha do progresso, da sobrevivência, do desenvolvimento. Aquilo que, em muitos casos, não se percebe porque é uma ideia estreita que se perde no limite da parcialidade (LEVY, 1986, p.62). 
Nesse contexto, o autor trata o empresário como o ser, o líder de ação, o criativo já que o pensamento estratégico é uma iniciativa que muitas vezes não se percebe por ser visto parcialmente.

Como Mintzberg (2006): "Posicionamento já foi o núcleo da estratégia, é rejeitado como sendo muito estático para os dinâmicos mercados atuais e as tecnologias mutantes. Segundo o novo dogma, os rivais podem copiar rapidamente qualquer posição de mercado e a vantagem competitiva é na melhor hipótese, temporária".

Atualmente, posicionamento é uma dinâmica constante que exige muito controle e estratégia. Para a empresa acompanhar o mercado deve ser bem estruturada a inteligência competitiva com ações claras e foco. Não se trata do posicionamento como núcleo da estratégia, e sim, o resultado do contexto e do mercado atual.

Para o líder de ação conforme Oliveira, Djalma (2010) a diferença entre objetivo e desafio é que objetivo é o alvo ou ponto que se pretende alcançar. Já desafio é a quantificação, com prazos definidos, do objetivo estabelecido. E para serem alcançados, os desafios exigem esforço extra.

No entanto a união dos dois conceitos seria a ideal, já que o esforço extra também alcançará o objetivo, e se o líder almejar o crescimento da empresa, dele também será necessária maior dedicação, resultando assim em um somatório de esforços e objetivos de seus dirigentes. Portanto, é importante seus executivos de empresas e funcionários considerem os objetivos empresariais como os seus próprios objetivos pessoais, sendo imprescindível alta motivação em direção aos resultados esperados.

\subsubsection{Planejamento estratégico}

Os pioneiros da administração como Taylor, Fayol, Mayo e outros renomados percursores da Administração clássica, tinham as suas visões voltadas para o interior das organizações.

Após a Segunda Guerra Mundial, o ambiente externo passava cada vez mais a influenciar as organizações, pois a produtividade não significava mais o sucesso. A organização tinha que atender a demanda do mercado. Deste problema surgiu o "Planejamento Estratégico".

No início consistia apenas em uma análise racional das oportunidades, ameaças, pontos fortes e fracos de uma organização de produção, e a partir dessa análise elaborava-se uma 
Saber Humano, ISSN 2446-6298, V. 8, n. 12, p. 143-167, jan./jul. 2018.

"estratégia" que conseguisse uma compatibilização positiva dessas variáveis com os objetivos da organização (ANSOFF, 1981).

Em concordância Fischmann e Almeida (1995) conceituavam o Planejamento Estratégico como:

Técnica administrativa que, através da análise do ambiente de uma organização, cria a consciência das suas oportunidades e ameaças e dos seus pontos fortes e fracos para o comprimento da sua missão e, através desta consciência, estabelece o propósito de direção que a organização deverá seguir para aproveitar as oportunidades e evitar os riscos. (FISCHMANN e ALMEIDA, 1995, p. 25)

Dentro deste contexto, Ansoff (1991, p.20) considera que o planejamento estratégico deveria oferecer respostas a duas necessidades, a saber:

- Necessidade de preparar a empresa para o futuro que não seria uma simples projeção do passado; e

- Necessidade de preparar a empresa de maneira abrangente e sistemática.

Planejamento é especificar a própria ação, o próprio investimento, sobre o concreto do próprio escopo já definido, não mais geral. Isso leva tempo e, enquanto se faz isso, deve-se ter um processo de abertura e ampliação.

Em 1954 a contribuição de Peter Ducker para o desenvolvimento do planejamento foi fundamental a partir de, principalmente, duas concepções. Ele apresentou sua abordagem de Gestão por objetivos (Management by objectives, MBO), destacando que uma organização sem objetivos é como se fosse um navio sem leme. Ressalta ainda que estabelecer objetivos e monitorar seus progressos deveria permear toda a organização, de cima a baixo. Outra contribuição refere-se ao seu pioneirismo ao predizer que as organizações seriam menos hierarquizadas no futuro, com a predominância dos trabalhos desenvolvidos por equipes multifuncionais, cuja liderança seria exercida por aquele com mais conhecimento (Knowledge worker). Ele introduzia, assim, o conceito do chamado "Capital Humano".

Sendo o planejamento a estrutura dos níveis de decisões, com o foco no prazo, relacionando com os objetivos da empresa, cada gestor para obter o resultado deve acompanhar e gerenciar continuamente sua equipe.

O planejamento tático constitui planos de médio prazo, um pouco mais detalhados que o planejamento estratégico. A diferença do planejamento estratégico para o planejamento tático é que o primeiro é voltado para a organização como um todo, já o segundo é orientado as áreas e 
departamentos da empresa, sendo que no detalhamento constarão os meios para atingir os objetivos e metas da organização.

Figura 2 Níveis de decisões e tipos de planejamento.

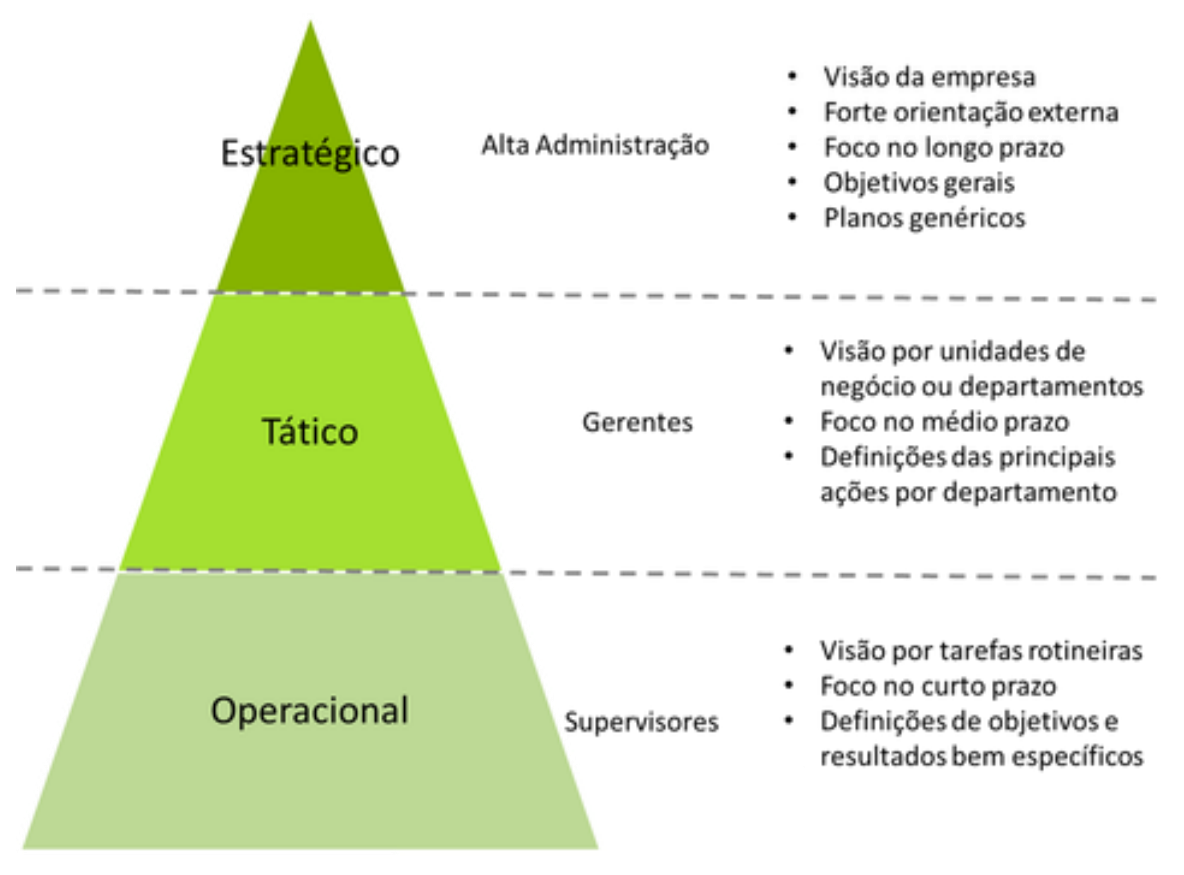

Fonte: Oliveira, Djalma (2010) p.22

De forma bem resumida, a imagem relaciona os tipos de planejamentos aos níveis de decisões, com o foco no prazo, relacionando com os objetivos da empresa e a abrangência da visão da empresa, por unidade ou departamentos e por tarefas rotineiras.

\subsection{Sustentar um desempenho superior}

Por meio de um processo definido e implementado que dá certo, traz resultado, o mais difícil é manter o desempenho num mundo globalizado e cada vez mais competitivo, mesmo informatizado, mesmo atento a todas as situações que favorecem o que realmente faz diferença, que é a inteligência competitiva. Por meio de operações de busca com gestores à frente do negócio e com conhecimento específico, uma empresa pode detectar mudanças que tenham acontecido em seu ambiente de negócios, colocando-se em uma posição para tomar decisões mais efetivas. 
Saber Humano, ISSN 2446-6298, V. 8, n. 12, p. 143-167, jan./jul. 2018.

A alta administração deve conduzir o esforço da inteligência competitiva, mas todos os colaboradores devem ser envolvidos e realmente capacitados para contribuir com esse esforço (LUECAL; DAHL, 1995; FULD, 2008).

\title{
2.2.1 Inteligência competitiva e envolvimento das pessoas para o crescimento da empresa (competência competitiva)
}

A inteligência competitiva advém do escopo e da vantagem, sendo o escopo amplo ou estreito, neste caso, o cliente a atender. Já a vantagem competitiva trata do custo ou diferenciação, onde o custo atende um alvo ou escopo amplo e a diferenciação um alvo e escopo estreito.

"O líder deve ter conhecimento da sua inteligência em modo total, porque a inteligência é a energia-base que funda todas as outras formas de energia”. (Meneghetti, 2010, p. 339).

De acordo com Meneghetti (2010), “competência significa que existe um primado de saber e fazer uma profissão específica e ainda fazer melhor que os outros e exige um exercício cotidiano. Essa competência deve ser competitiva para obter com a competitividade a antecipação e com isso garantir a qualidade do seu serviço prestado em detrimento aos demais.”.

A vantagem competitiva advém muitas vezes do envolvimento das pessoas-chave. Neste artigo, evidencia-se o quanto a competência e vantagem competitiva estão ligadas, sempre em antecipação e com ganho de mercado.

\begin{abstract}
A vantagem competitiva não pode ser compreendida observando a empresa como um todo. Ela tem sua origem nas inúmeras atividades distintas que uma empresa executa no projeto, na produção, no marketing, na entrega e no suporte de seu produto. Cada uma destas atividades pode contribuir para a posição dos custos relativos de uma empresa e criar uma base de diferenciação (PORTER,1947 p. 31).
\end{abstract}

$\mathrm{Na}$ indústria, a questão central estratégica competitiva é a posição relativa que determina se a rentabilidade de sua empresa está abaixo ou acima da média da indústria, podendo considerar dois pontos de vantagens um baixo custo de produção ou a diferenciação. 
Figura 3: Vantagem competitiva

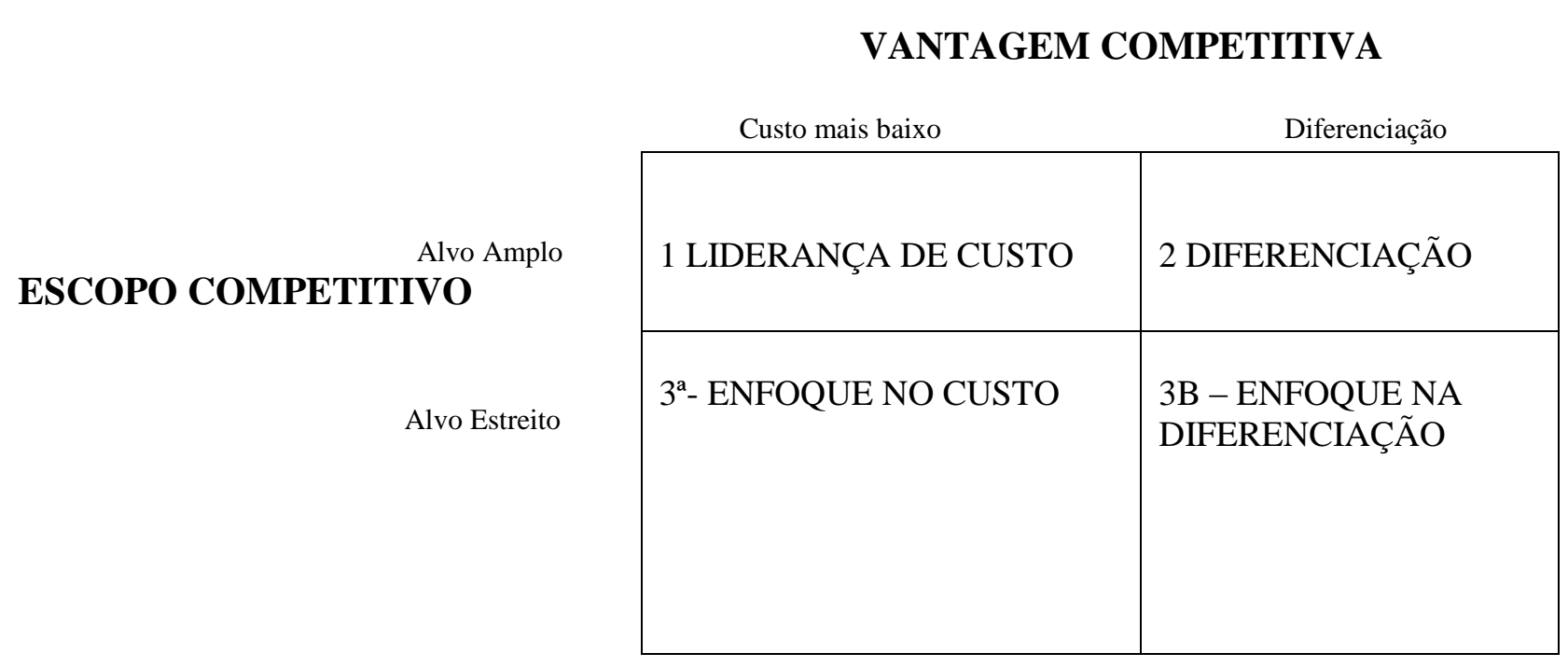

Fonte: POTER, Michael E. Vantagem competitiva (1992, p. 10)

Para a empresa ter a vantagem competitiva, deve fazer uma escolha sobre o tipo de vantagem que ela busca obter e sobre o escopo dentro do qual irá alcançar, sendo um o custo e o outro a diferenciação.

\subsection{Breves ideias acerca da ontopsicologia na gestão da empresa}

\subsubsection{Definição de líder}

De Geus, (1997) destaca que o propósito do pensamento estratégico não é simplesmente elaborar plano, mas mudar os modelos mentais dos tomadores de decisão. Segundo De Geus (1997) a prática do pensamento estratégico, que tem ainda o atributo de harmonizar a visão de mundo de seus participantes.

O líder, por ser um tomador de decisão, deve sempre ter sua visão voltada ao novo, ao amplo do negócio, da empresa, não ser uma pessoa limitada e com resistência de forma a prejudicar ou interferir em mudanças importantes que poderiam contribuir e favorecer a empresa.

O líder é a pessoa-vetor com capacidade de síntese de um contexto de relações; é o centro operativo de diversas operações e funções. Possui uma hierarquia de funções: as constrói, as controla e as desenvolve, sempre em relação a um escopo definido. O líder é 
Saber Humano, ISSN 2446-6298, V. 8, n. 12, p. 143-167, jan./jul. 2018.

um indivíduo que sabe fazer as relações com vantagem; é um vetor proporcional de diversos pontos-força. É uma pessoa que - prefixado um escopo- busca e faz os meios e as pessoas funcionais ao escopo, De tudo que acontece em relação ao seu contexto, ele permanece a mente. (MENEGHETTI, 2010 p. 339)

A partir do século XIX os estudos sobre o tema foram organizados de forma sistemática. Atualmente, existem inúmeras abordagens, perspectivas e definições recorrentes à liderança, contudo, há consenso entre os estudiosos de que liderança revela influência do líder sobre o liderado. Neste estudo o assunto será tratado como e de que forma cada gestor faz o seu trabalho e gera resultado para a empresa.

O líder, enquanto função á eficiência e evolução do corpo justifica-se exclusivamente pela capacidade dos resultados. Portanto, deve auscultar e saber tudo para depois discriminar e decidir sozinho. Quando aceita a democracia a história pode justificá-lo, mas a vida o considera falido. (MENEGHETTI, 2013, p. 104)

Meneghetti (2013) complementa ainda que o líder é uma causalidade da natureza, e não é genética. Por nascimento dá-se um potencial, porém, esse potencial, se não é ajudado pelo ambiente, não chega a manifestar-se. Sendo assim, existe uma autocriação individual que inclui potencial, egoísmo e instinto de ser o melhor.

\subsubsection{Não existe função sem pessoa}

A grande riqueza do business é ter e contratar a pessoa que se identifica com o projeto, que se realiza dentro dele, faz função e sem ela seria difícil a mesma performance. Esse é o ponto em que identificamos que toda função precisa de pessoas capacitadas, competentes, sem as quais as atividades fins não seriam as mesmas, pois elas sabem se submeter ao escopo da empresa em ordem econômica. "A primeira riqueza é sempre a pessoa que goste e queira fazer, nesta ordem se prepara os demais para sempre ter outros a fazer e continuamente fazendo função a empresa com sucessão e personalizando aquele que será o próprio futuro core business" (MENEGHETTI, 2013, p. 270). 


\section{Metodologia}

\subsection{Abordagem de pesquisa ou tipo de estudo}

Para a realização desta pesquisa qualitativa, utilizou-se o método exploratório. Tendo em vista o objetivo do estudo, foi realizada uma pesquisa de natureza qualitativa.

Para tanto, as tarefas e etapas da pesquisa foram: a) esboçar inicialmente o tema de estudo, delimitação do tema e problema de pesquisa; b) estudar e escrever a fundamentação teórica; c) definir a metodologia de pesquisa; d) aplicar os instrumentos de coleta de informação da pesquisa; e) analisar as informações coletadas na pesquisa; f) escrever os resultados; g) finalizar a escrita do relatório de pesquisa e suas conclusões; h) apresentar a pesquisa realizada.

\subsubsection{Participantes da pesquisa}

O critério adotado para a escolha dos entrevistados foi motivado pela possibilidade de conhecer uma empresa competitiva em seu segmento de negócio. A empresa é líder no segmento de calçados, sendo uma das maiores fabricantes brasileiras.

Os sujeitos da pesquisa são: gestores e pessoas de referência para o desenvolvimento e acompanhamento do Planejamento, por devidos setores, e que de alguma forma contribuam para entender as demandas internas e externas, com o objetivo competitivo e de mercado, contribuindo na construção do plano de ação e do planejamento estratégico.

Tabela 1- Caracterização da Amostra da pesquisa:

\begin{tabular}{|c|c|c|c|c|}
\hline Entrevistado & Sexo & Função & $\begin{array}{c}\text { Quantos } \\
\text { liderados diretos }\end{array}$ & Tempo de empresa \\
\hline 1 & M & Gerente Industrial & 820 & 20 anos \\
\hline 2 & M & Gerente Industrial & 914 & 6 anos e 6 meses \\
\hline 3 & M & Gerente Industrial & 800 & 7 anos e 5 meses \\
\hline 4 & M & Gerente de planejamento & 113 & 20 anos \\
\hline 5 & M & Diretor Industrial & 10.000 & 32 anos \\
\hline
\end{tabular}


Fonte: Dados coletados na pesquisa.

Convém salientar que todos os sujeitos da pesquisa já trabalharam em vários setores: o número 1 iniciou como supervisor, passou a coordenador, gerente em duas filiais, trabalhou no planejamento industrial, gerente de compras e voltou à gerente da atual filial. O número 2 iniciou como supervisor de costura, corte, ateliê e depois assumiu a gerência da atual filial. Número 3 iniciou como supervisor de produção, e depois assumiu a atual filial como gerente. Número 4 iniciou como cronometrista, cronoanalista, coordenador de processos, gerente industrial e agora gerente de planejamento. Número 5 iniciou como supervisor de produção, gerente de produção, diretor de compras, diretor de produtos, desenvolvimento de produtos e agora diretor industrial.

Nos procedimentos de coleta de informações, buscaram-se identificar as rotinas e sua interpretação pelas pessoas envolvidas, onde e de que forma os praticantes da estratégia interagem aos desenvolver suas atividades.

\subsection{Procedimentos de coleta de informações}

As informações deste estudo foram coletadas por meio de entrevistas pessoais, em profundidade por meio de roteiro de entrevista, cuja duração média girou em torno de 30 minutos. As entrevistas foram gravadas, e, posteriormente, transcritas e analisadas com a adoção da técnica de Análise de Conteúdo, que visa captar as características essenciais, os significados, as convergências e as divergências dos conteúdos das entrevistas (BARDIN, 2008).

\subsubsection{Procedimentos de análise das informações}

Para a análise das informações, foi feita a preparação do material escolhido, seguindo as etapas sugeridas por Flick (2009): a transcrição das gravações e a leitura cuidadosa das mesmas. A preparação permitiu a sintetização das falas, eliminando-se os trechos que não seriam relevantes para responder ao problema de pesquisa e as repetições. Seguiu-se com a codificação dos textos em eixos de acordo com os principais termos utilizados para embasar o estudo. Os termos deram origem às dimensões analisadas, ou seja, as formas de diferenciação e atuação de cada gestor. Assim, realizou-se a coleta de informações primárias mediante entrevista presencial 
centralizada no problema, e a análise foi baseada na técnica de análise de discurso (FLICK, 2009; GIL, 2002).

\section{Descrição dos resultados da pesquisa}

\subsection{Análise qualitativa dos discursos dos participantes da pesquisa}

A partir da análise detalhada do conteúdo das entrevistas com os 5 sujeitos entrevistados, foram construídas as categorias teóricas empíricas abaixo apresentadas.

As categorias iniciais configuram-se como as principais impressões acerca da realidade organizacional estudada. Resultaram do processo de codificação das entrevistas transcritas um total de 19 categorias. Cada categoria constitui-se dos trechos selecionados das falas dos entrevistados e, também, conta com o respaldo do referencial teórico.

Inicialmente a pesquisadora trabalhou com as palavras-chave que resultaram na tabela abaixo as dezenove categorias iniciais, com os conceitos norteadores descritos abaixo:

Tabela 1.1- Categorias iniciais e conceitos norteadores

\begin{tabular}{|c|l|}
\hline \multicolumn{1}{|c|}{ Qualidade } & Produto que atenda o cliente e com preço justo \\
\hline Tecnologia & Sempre máquinas de ponta \\
\hline & Compras/ criação e fábrica \\
\hline Conquistando a perfeição-programas & Ações realizadas e pontos de melhorias \\
\hline Treinamentos internos & $\begin{array}{l}\text { Meritocracia e 77 \% dos gerentes formados dentro da } \\
\text { empresa }\end{array}$ \\
\hline Cultura da empresa e do diretor & Diretor presente e com conhecimento amplo \\
\hline Pessoas comprometidas e motivadas & Conquistando valorização e motivação \\
\hline Perfil de líder e visão de liderança & $\begin{array}{l}\text { Formação contínua e com conhecimento do produto } \\
\text { produzido }\end{array}$ \\
\hline Trabalho com compromisso e foco & Objetivo e resultados claros \\
\hline & Acompanhamento diário e reuniões sempre que preciso \\
\hline Medir resultado & $\begin{array}{l}\text { Tem controle e acompanha todos os supervisores e a } \\
\text { fábrica }\end{array}$ \\
\hline 100\% informação do gestor & Trabalho em equipe e comprometimento de todos \\
\hline Diretrizes claras e simples & \\
\hline &
\end{tabular}


Saber Humano, ISSN 2446-6298, V. 8, n. 12, p. 143-167, jan./jul. 2018.

\begin{tabular}{|c|l|}
\hline \multicolumn{1}{|c|}{ Mapa diário } & $\begin{array}{l}\text { Relatório diário com posição real com vários índices, } \\
\text { desde histórico de produção, capacidade... }\end{array}$ \\
\hline Eficiência por fábrica & $\begin{array}{l}\text { Com o relatório é possível identificar possíveis atrasos } \\
\text { e ajustar }\end{array}$ \\
\hline $\begin{array}{c}\text { Programação linear média/produção e } \\
\text { entrega }\end{array}$ & $\begin{array}{l}\text { Medindo a média da produção para não acontecer } \\
\text { atrasos em entregas e possíveis falhas }\end{array}$ \\
\hline Cliente, concorrência e mercado & $\begin{array}{l}\text { Cliente obrigação de ser atendido, mercado com } \\
\text { necessidade atendida e concorrência vamos fazer } \\
\text { melhor }\end{array}$ \\
\hline Atendendo aos pedidos & $\begin{array}{l}\text { Vende mais esse, vamos ajustar e produzir mais, a } \\
\text { fábrica não atende vamos passar para outra e atender }\end{array}$ \\
\hline Estrutura de atendimento à demanda & Todas as fábricas podem produzir todas as linhas \\
\hline $\begin{array}{c}\text { Fornecedores e terceirizados (que são } \\
\text { contratos de terceiros para produção) }\end{array}$ & $\begin{array}{l}\text { Sempre mais de um fornecedor, para nunca ficar sem } \\
\text { atender a empresa e prejudicar a entrega. }\end{array}$ \\
\hline
\end{tabular}

Fonte: Dados coletados na pesquisa

Com base nas informações coletadas, o estudo foi estruturado com as categorias iniciais e com os conceitos norteadores, buscando identificar produtos e produção, depois comportamentos e cultura da organização, e ainda, como a informação é disseminada no âmbito da empresa.

Após definidos os conceitos norteadores, foram necessárias categorias intermediárias, nomeadas em conformidade com os dados que as constituíram, pautadas nas narrativas dos entrevistados, referencial teórico e observações. São quatro categorias intermediárias, cujo processo de formação está ilustrado na Tabela 1.2.

Tabela 1.2: Categorias intermediárias

\begin{tabular}{|l|l|}
\hline Intermediárias & Conceitos norteadores \\
\hline \multicolumn{1}{|c|}{ Inovações e técnicas gerenciais } & $\begin{array}{l}\text { Qualidade para atender com preço competitivo e com grandes } \\
\text { investimentos } \\
\text { Produtos em grande qualidade para o custo reduzir. }\end{array}$ \\
\hline & $\begin{array}{l}\text { Programas internos bem desenhados, com o perfil do diretor e com } \\
\text { sua constante presença. }\end{array}$ \\
\hline
\end{tabular}




\begin{tabular}{|c|c|}
\hline Valores da organização & $\begin{array}{l}\text { A meritocracia e o reconhecimento de fazer carreira mantem às } \\
\text { pessoas comprometidas e com foco para seu desenvolvimento. O } \\
\text { líder também busca sempre novos funcionários para dentro da } \\
\text { empresa para desenvolver todas as capacidades desde o } \\
\text { comportamento quanto a formá-lo um líder. }\end{array}$ \\
\hline Gestão e eficiência & $\begin{array}{l}\text { Gestão de produtividade e de lucratividade medindo e acompanhando } \\
\text { diariamente através de números e ainda no chão da fabrica. No } \\
\text { planejamento a informação é } \\
\text { clara e objetiva, metas possíveis e com total aceitação do desafio. } \\
\text { Sua preocupação é atender aos pedidos e manter a qualidade para } \\
\text { atingir o resultado }\end{array}$ \\
\hline Inteligência competitiva & $\begin{array}{l}\text { Atende o cliente em primeiro lugar, sempre suprindo as expectativas } \\
\text { dele. } \\
\text { Mercado se está fazendo algo diferente, o que vamos fazer de novo } \\
\text { para concorrer? } \\
\text { Para atender a demanda, a estrutura da organização tem que ser } \\
\text { infalível. } \\
\text { Nossa empresa tem que ter autonomia e não depender de terceiros. }\end{array}$ \\
\hline
\end{tabular}

Fonte: Dados coletados na pesquisa

A contextualização dos tópicos abordados na tabela 1.2 direcionou para as categorias intermediárias que atendiam aos dados coletados na pesquisa.

A constituição das categorias finais é formada por três categorias denominadas: Inovações e técnicas gerenciais de produtos, Valores da Organização, Gestão e eficiência mantendo um desempenho superior - esta última trata da união da gestão e eficiência com a Inteligência competitiva da categoria intermediária.

Construídas com o intuito de respaldar as interpretações e inferir os resultados, as categorias finais representam a síntese do aparato das significações, identificadas no decorrer da análise dos dados do estudo.

\subsection{Inovação e técnicas gerenciais de produtos}


Com inovação e uma gestão eficaz, a empresa estudada é líder no segmento de calçados, sendo uma das maiores fabricantes brasileiras. Lançadora de tendências, a empresa leva seus produtos, semanalmente, a mais de 85 países, empregando mais de nove mil colaboradores de forma direta. Produzindo valores, as marcas do grupo - divida em seis grandes marcas já renomadas e conceituadas pelos consumidores - entregam qualidade, conforto e muita moda para todos os estilos.

Conforme o gerente industrial, a cada novo produto, e no planejamento anual, tudo é levado em conta, desde a capacidade instalada de cada filial, para a divisão de linhas e produtos. Capacidade instalada, equipamentos e pessoas têm que estar perfeita proporcionalidade, sem deixar de voltar o olhar também para as pessoas no sentido de possibilidade de crescimento objetivo macro. Os gerentes das filiais afirmam que sua maior preocupação é o produto e a qualidade da produção, já que o suporte de matéria prima e equipamentos são supridos pelos setores responsáveis. Em alguns casos, é necessário atender e preparar a equipe com treinamentos internos.

O entrevistado 1 destaca:

"Se trabalha pensando, não aquilo que eu quero, mas aquilo que o cliente quer, o meu entendimento de sapato ele te gera muita variação, ai eu achar que isso pode, mas para o cliente não pode, tu tens que se adaptar daqui a pouco eu acho ridículo uma determinada combinação, mas é aquilo que o cliente quer eu tenho que produzir...o cliente compra aquilo que ele quer mas ele tem que receber aquilo que precisa." (sujeito1)

Quanto ao produto o entrevistado 1 aborda:

"A gente faz um produto às vezes mais elaborado, existem mais componentes, então tu tens que ter uma estrutura um pouquinho diferenciada, tem que ter um alinhamento perfeito. Então, conhecimento técnico, conexão entre a equipe, entre os setores tudo em uma sincronia somente assim funciona." (Sujeito 1)

Entrevistado 2

"Se todos trabalharem em sincronia isso funciona, esse foco no objetivo, no resultado. Um quebrando a cadeia produtiva prejudica o outro em tempo e em produto. Tempo e qualidade são duas coisas que estão absolutamente juntas, não adianta entregar qualidade fora do prazo ou vice-versa." (Sujeito 2)

Entrevistado 3

"Recebemos as diretrizes, nos dão o sustento do que for necessário, e cabe a cada gerente a cada unidade montar a sua estratégia... pessoas, maquinários, tipo de 
Saber Humano, ISSN 2446-6298, V. 8, n. 12, p. 143-167, jan./jul. 2018.

produto, prestadores de serviços para tal qualificação, treinamento interno, funções novas e tudo acompanhado passo a passo" (Sujeito 3)

Quanto ao cliente, o entrevistado 3 diz que "a exigência dele é o nosso amanhã, tem que estar aberto a buscar, a criar e servir ele da maneira que ele quer...”.

Quanto às técnicas gerencias, o entrevistado 4 comenta dos padrões:

"Padrões eles são submetidos o tempo inteiro a serem melhorados, esse é um diferencial que as pessoas não enxergam de fora, mas acontece... às vezes um padrão não chegou a rodar nas dez unidades ao mesmo tempo porque antes de conseguir implementar já se achou uma ideia melhor. O padrão é momentâneo e às vezes não perpetua na nossa empresa". (Sujeito 4)

Quando questionado a atender a demanda o entrevistado 5 diz:

"cada unidade tem sua marca titular, porém se tem pedido em excesso de uma marca tem outra unidade que vai atender, a demanda passa para outra filial e equilibra, atende o mercado uniforme. Nós temos uma programação linear de média de 17 dias úteis de entrega e em 20 a 30 dias para o mercado a nível nacional. Outro ponto é a matéria prima, não tem nenhuma matéria prima que só um único fornecedor tenha desenvolvido no mínimo dois, se tiver demanda maior o outro ajuda a produzir"(Sujeito 5)

A tecnologia é um ponto de extrema importância. A empresa tem as melhores máquinas e os clientes confirmam nas visitas que a empresa atende a demanda e mantém a qualidade por investir em maquinário e por proporcionar um ambiente agradável dentro de cada unidade, o que faz com que a mão de obra também agregue valor ao produto, por trabalhar com satisfação.

Um dos segredos da empresa é essa dinâmica que fica evidente em cada entrevistado, por ser muito claro que o cliente é prioridade, técnica e conhecimento são primordiais, assim como a equipe sincronizada, tempo e qualidade na entrega. Por ser muito dinâmico, são reavaliados várias vezes os padrões, submetidos o tempo todo a melhorias. Quanto à demanda, as fábricas podem atender demandas de outras, já que a produção e a venda de produtos dependem do que vende mais em cada momento.

Sendo uma das bases do processo da estratégia empresarial o objetivo, por meio dos recursos, circunstâncias e definição da estratégia, os entrevistados apresentaram que também levam muito em consideração o produto o que o cliente quer. Sendo assim, o objetivo também é o cliente, e não só o resultado. 
Avaliar os recursos e circunstâncias significa conhecer a visão atual da empresa.

\subsection{Valores da organização}

Nos valores da organização encontrou-se:

Programas internos bem desenvolvidos, com o perfil do Diretor e com sua constante presença, a meritocracia e o reconhecimento de fazer carreira mantêm as pessoas comprometidas e com foco para se desenvolver.

Com base na estrutura dos envolvidos na pesquisa, é demonstrado abaixo como atualmente a empresa apresenta e desenvolve o seu processo da estratégia para o planejamento.

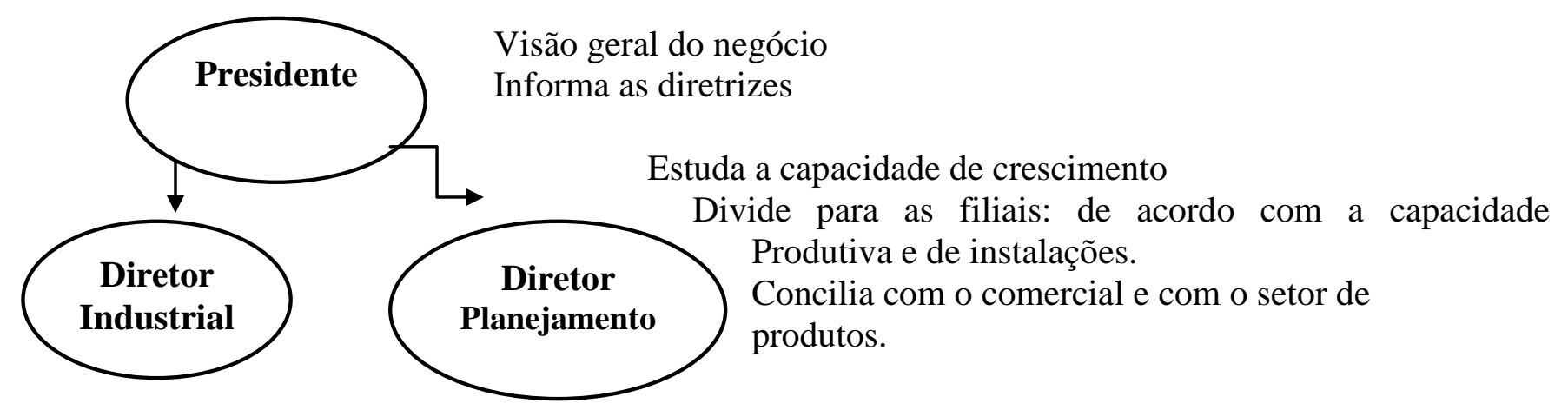

Em cima das premissas, estuda, planeja e sincroniza com as demais, primeiramente na visão dos números.

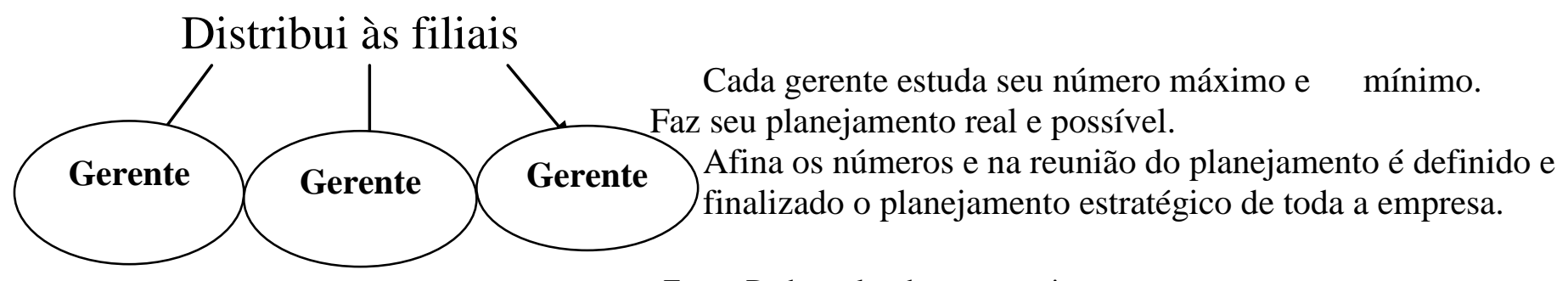

Fonte: Dados coletados na pesquisa

O planejamento macro da estratégia parte do presidente, que repassa as diretrizes (visão global do negócio). O diretor comercial e o Diretor de Planejamento, em algumas reuniões 
definem, dentro da capacidade produtiva e de instalações, as possibilidades de crescimento, conciliadas com o setor comercial e de produtos.

O Gerente industrial, em cima das premissas, estuda, planeja e sincroniza com as demais, visando primeiramente os números. Depois distribui aos Gerentes das filiais, dentro de suas capacidades produtivas, números máximos e mínimos. Cada Gerente faz o seu planejamento de forma bem real, atingível. O Gerente industrial filtra e compacta todas as informações e depois leva para a reunião do planejamento para definições e finalização.

Fica evidente que não é só uma empresa que trabalha com produção em série, mas uma empresa que combina a produção em série com a possibilidade de os colaboradores expressarem suas opiniões e conhecimentos prévios, e, ao mesmo tempo, desenvolverem novos conhecimentos na própria empresa em cursos de treinamentos. Essa é a satisfação de colaborar com o dia a dia da empresa fazendo a diferença.

Em uma aula ministrada pelo Diretor Presidente, um dos alunos fez o questionamento: como escolhe as pessoas para trabalhar com o senhor, já que não pode estar o tempo todo nas filiais? Ele respondeu:

"A maneira de eu estar presente em todos os locais é com o método, disciplina, unidade de ação que o Conquistando a perfeição tem. E claro que eu tenho que ser exemplo e ser coerente e assim a empresa se espelha e meus colaboradores também, me faço presente assim." (Diretor Presidente)

Entrevistado 1 aborda:

"Nossa equipe é toda formada interna, nós dificilmente buscamos fora, por meritocracia eles vão crescendo, vão evoluindo e chegando à função que eles precisam... Desponta uma pessoa a gente coloca em treinamento.". "O "Conquistando" te dá essa visão maior por todos verem as apresentações dos demais e assim conhece mais do que só o seu setor" (Sujeito1)

Entrevistado 2 traz o senso de competitividade por meio do programa:

"O projeto Conquistando a Perfeição, neste projeto as pessoas participam cada um dentro do seu setor mostrando seus resultados, seus números e ao mesmo tempo olhando o resultado e os números do restante da equipe e dos demais, isso gera uma competitividade. Então, não tem como se acomodar no resultado ruim olhando um desempenho positivo dos demais colegas, ou das outras unidades." (Sujeito 2)

Ele ainda ressalta que a equipe incorpora bem as metas, de forma positiva, por ser competitiva, e gera a pró-atividade na expectativa de mostrar com orgulho o resultado atingido. 
Já em uma das filiais o Gerente destaca com orgulho que tem turmas com aulas para formação contínua e diária, trabalhando os que já existem e novos líderes.

"Fomentar as novas lideranças, a gente tem uma turma de 18 colaboradores direto da produção, onde por meritocracia, eles por se destacarem nas funções, a gente coloca em uma sala de aula e procura apresentar para eles como funciona a maneira de se relacionar com as pessoas, a maneira de tu obteres a alegria delas trabalharem, o poder de convencer as pessoas, elas precisam gostar de fazer o que fazem.” (Sujeito 3)

Ainda com os valores da organização e a cultura implantada, o gerente de planejamento comenta como ele trabalha e pelo perfil da função de repassar informação dizendo:

"Eu tenho que repassar todo tipo de informação, me espelho muito no que o Diretor faz, ele tem uma característica que é repassar informação, eu tenho que saber coletar e tenho que repassar, então como líder vejo que o conhecimento e a informação deve ser de todos para facilitar todos os processos e o resultado final acontecer para todos." (Sujeito 4)

Um dos pontos que todos os gerentes concordam é que a informação é muito clara e objetiva, desde o Diretor até os encarregados.

O entrevistado acrescentou que:

"A empresa vem fazendo há nove anos o nosso projeto interno na empresa e ficou visível o crescimento, a unidade de ação entre todas as empresas, entre todas as áreas, então é neste formato que elaborou uma responsabilidade que a gente trabalha os pontos principais, mais importante que é trabalhar em cima de pessoas... trabalhar sempre as melhorias, não procurar culpados e sim a solução, um trabalho ágil, dinâmico e uma unidade de ação que vejo como principal ponto. O Conquistando é uma melhoria constante" (Sujeito 5)

Como De Geus (1997) destaca, o propósito do pensamento estratégico não é simplesmente elaborar um plano, mas mudar os modelos mentais dos tomadores de decisões. Meneghetti (2010) diz que o líder é a pessoa vetor com capacidade de síntese de um contexto de relação. Sendo o líder aquele que se realiza no projeto e se identifica com ele, faz função, já que toda função precisa de pessoa capacitadas e com competência que se submetem aos escopos da empresa em ordem econômica.

\subsection{Gestão e eficiência}

Com todo o processo bem definido e com o modo de ação bem claro e objetivo, a empresa consegue se manter líder de mercado. 
Essa empresa tem a sua cultura bem definida internamente, as equipes procuram trabalhar muito alinhadas, com união, entusiasmo, com conhecimento e por ter uma formação interna bem trabalhada se torna um ponto força muito focado no objetivo e gerando sempre de forma positiva o resultado. A incorporação das decisões, por ser uma dinâmica já bem clara e definida desde o Diretor até os encarregados, acontece de maneira suave, positiva e como um desafio que se incorpora em todos, gerando no conjunto o resultado esperado.

O plano de ação de cada gestor é reavaliado a cada momento, já que a dinâmica da empresa é rápida e o acompanhamento é direto. É perceptível qualquer ajuste ou alteração a ser feito, em tempo real, mesmo nos casos de tempo ou qualidade, já que disto vai depender o resultado. $\mathrm{O}$ gestor precisa enxergar o macro, além dos demais, ter antecipação e conhecer todo o processo, por esse motivo que os gestores geralmente são formados internamente e com isso a cultura organizacional já é de conhecimento de cada um. O planejamento estratégico da empresa é alterado dentro da realidade e do contexto, um exemplo segundo entrevistado 4:

\footnotetext{
"se a programação era vender sandálias e está vendendo mais rasteirinhas, o resultado final deve ser o mesmo, já que podemos alterar no planejamento o resultado com a venda de rasteirinhas. Se nos propomos a crescer $\mathrm{x} \%$ e notamos que podemos crescer XX\%, vamos explorar e mudar o planejamento para o melhor resultado. Se o frete aumentou mais do que previmos, vamos diminuir em outro item para atender o resultado previsto". (Sujeito 4)
}

Isso tudo com acompanhamento e foco contínuo no resultado. Pode-se notar que em um dos ambientes visitados na mesa de cada setor estavam expostas as melhorias sugeridas, em que a visualização diária reporta ao objetivo esperado. As estratégias são estudadas e discutidas diariamente, cada situação é analisada e levada ao consenso com os envolvidos.

Dentro da empresa estudada segundo o entrevistado 4:

"nada é estático, e o planejamento não é um planejamento estratégico longo, existe um macro que é da parte de direção, o planejamento de empresa hoje é tático e por isso as coisas acontecem." (Sujeito4)

Quando perguntado como estrutura o plano de ação, o gestor um comenta:

"toda a informação é disseminada, claro que tenho que transformar em mais direcionada para cada área, mas esse é o método da empresa, tenho a possibilidade de fazer que eu enxergo para frente, então consigo me organizar... Tem que estar ligado, não posso me desaperceber de nada e a equipe também." (Sujeito 4)

O Entrevistado 2 trata do orgulho de trabalhar na empresa: 
Saber Humano, ISSN 2446-6298, V. 8, n. 12, p. 143-167, jan./jul. 2018.

"A gente tem muito orgulho de trabalhar nesta empresa, uma empresa de ponta, temos hoje a certeza que é a empresa de calçados com melhor estrutura tecnológica do mundo... Tem uma gestão voltada, é competitiva, e nos torna competitivo e a prática disso é que nos coloca como pessoas competitivas também estão aprendendo com isso dia a dia." (Sujeito 2)

\section{O Entrevistado 5 comenta do foco em produzir:}

"Um planejamento bom de produção. Bem definido, o que fazer, como fazer e quando fazer. O gerente hoje tem o compromisso de fazer o processo bem feito, não tem que se preocupar com os outros, nós temos o setor de planejamento, o setor de compra, de qualidade. O gerente hoje tem que se preocupar com o processo. Fazer bem feito aquilo que ele é determinado para fazer, os produtos que ele faz, então tem que ter o foco de produzir bem." (Sujeito 5)

Os dirigentes da empresa entrevistados compartilham diversos pontos que ajudam a compreender e explicar o desempenho exitoso que a empresa vem apresentando nas últimas décadas e que a apresentação do trabalho mensal traz a satisfação de ter feito um bom trabalho e reconhece o que precisa ser mudado.O Gerente Industrial informa que "o preço de venda não vem só do custo, quem faz o preço é o mercado, é a área comercial que diz o que é caro e o que é barato".

Os custos controlados e análises de alocação dos custos na Empresa pesquisada também fazem essa vantagem competitiva, os fornecedores são sempre reavaliados e esses constantes trabalhos trazem um resultado no comportamento no custo de suas atividades de valor.

A alta administração deve conduzir o esforço da inteligência competitiva, mas todos os colaboradores devem ser envolvidos e realmente capacitados para contribuir com esse esforço (LUECAL; DAHL,1995; FULD, 2008).

Porter (1947) destaca, o desempenho engloba inúmeras atividades distintas que uma empresa executa no projeto, na produção, no marketing, na entrega e no suporte do produto, e isso traz vantagens e cria base de diferenciação.

\section{Considerações finais}

Esta pesquisa teve o objetivo geral de estudar como o gestor realiza seu plano de ação, no dia a dia da gestão, para garantir o resultado do planejamento estratégico da empresa, e propõe um aprofundamento da análise do papel destes atores no processo de alinhamento. 
Como pesquisa qualitativa exploratória, as evidências a seguir referem-se aos debates pelos gestores que atuam diretamente na indústria e com vasto conhecimento do setor. É importante destacar que a empresa em questão tem características organizacionais próprias e práticas de planejamentos estratégico distinto, ao mesmo tempo em que alcançam sucesso e liderança de mercado quando comparados à concorrência. Fica evidente que a rotina e práticas são recursos fundamentais para o êxito, que a preocupação de melhoramento dos processos conta com colher essas ideias direto dos colaboradores e isso traz uma significativa contribuição, e como os próprios gestores explicam: "proporciona uma unidade de ação muito maior e ainda com reconhecimento por poder expor e saber que está contribuindo com a empresa onde trabalha." (Sujeito 2)

Em alguns casos, a estratégia se define por meio de um sistema informal, baseado na interação interpessoal, e muitos casos num fluxo de informação de baixo para cima.

Já o planejamento macro da estratégia parte do presidente, que repassa as diretrizes (visão global do negócio). O diretor comercial e o diretor de planejamento, em algumas reuniões definem as possibilidades de crescimento, dentro da capacidade produtiva e de instalações, conciliando os objetivos com o setor comercial e de produção. O Gerente industrial, em cima das premissas, estuda, planeja e sincroniza com a demais a visão primeiramente dos números. Depois, distribui aos gerentes das filiais, dentro da capacidade produtiva, números máximos e mínimos. Cada gerente faz o seu planejamento de forma bem real e atingível, o Gerente industrial filtra e compacta todas as informações, e depois leva para a reunião do planejamento para definições e finalização.

A pesquisa desenvolvida na empresa demonstra que o resultado acontece porque cada gestor tem o controle de qualidade, equipamento de ponta, funções são bem definidas. $\mathrm{Na}$ formação dos gestores, o principal é conhecer os produtos que fabrica, com isso acompanha de perto todos os produtos, cada etapa da produção, e por conhecer todo o processo, controla o tempo e a qualidade diariamente, em lócus. A empresa tem um sistema de informação que também mede e valida o que o gestor está informando e se consegue atender todos os pedidos. É importante destacar que, na empresa, tudo é feito sempre priorizando o cliente. O prazer de trabalhar e fazer o seu melhor vem pela cultura implantada de reconhecimento e de meritocracia, desde o chão da fabrica aos gestores mais experientes. 
Quanto à pró-atividade de cada gestor e a unidade de ação, foi possível perceber que as decisões são incorporadas com naturalidade e com conhecimento, cada gestor trabalha com a mesma meta e com o foco no resultado, sendo possível ainda evidenciar as particularidades de cada um sem deixar de contribuir para o resultado. Portanto, é possível perceber que o Diretor da empresa trabalha as lideranças, fomentando o potencial de cada uma delas, sempre pensando no resultado para a empresa e para elas mesmas, como pessoas e profissionais.

\section{Referências}

ABIB, Gustavo; HOPEN, Norberto. O papel do consultor no processo de alinhamento estratégico. Rio de e Janeiro: RAC, 2015

ANDREWS, Kenneth R. El concepto de estratégia de la empresa. Barcelona. Universidad de Navarra, 1977.

ANSOFF; Igor. H. Corporate strategy: an analytic approach to business policy for growth and expansion. New York: McGraw Hill, 1965.

BETHLEM, Agricola. Estratégia empresarial: Conceitos, processo e Administração Estratégica. São Paulo: Editora Atlas S.A, 2009.

BULGACOV, Sergio; SANTOS, Pedro J P; MAY, Marcia R. A configuração da organização e sua relação com o planejamento estratégico formal e emergente. Rio de Janeiro: Cad. EBRAPE.BR, 2012

FLICK, Uke. Indrodução à pesquisa qualitativa. Porto Alegre.Artmed, 2009

CARVALHAL, Felipe; MUZZIO, Henrique. Economia criativa e liderança criativa: Uma associação (IM)Possível?. Porto Alegre: REAd, 2015. 
Saber Humano, ISSN 2446-6298, V. 8, n. 12, p. 143-167, jan./jul. 2018.

GIL, Antonio C. Como Elaborar Projeto de Pesquisa. São Paulo: Editora Atlas S.A, 2010

SUTTER, Marina B; MACLENNAN, Maria L F; POLO, Edison F; SREHLAU, Vivian I. Diferenciação e Competitividade da oferta de Moda Brasileira no mercado Internacional: São Paulo: Ram.Rev.ADM. Mackenzie, 2015.

LEVY, Alberto R. Estratégia em ação. São Paulo: Atlas, 1986

MARCONI, M.A \& LAKATOS, E. M. Fundamentos da metodologia científica. Atlas,2010

MENEGHETTI, Antonio. A psicologia do Líder. Recanto Maestro: Ontopsicológica Editora Universitária, 2013.

MENEGHETTI, Antonio. Manual de ontopsicologia. Recanto Maestro: Ontopsicológica Editora Universitária, 2010.

MENEGHETTI, Antonio. Psicologia Empresarial. São Paulo: FOIL , 2013

MINTZBERG, Henry; LAMPEL, Joseph; QUINN, James B; GHOSHAL, Sumantra. O processo da estratégia: conceitos, contextos e casos selecionados. Porto Alegre: Bookman, 2009

OLIVEIRA, Djalma de P R. Planejamento estratégico: Conceitos, metodologia e praticas. São Paulo: Editora Atlas S, 2010.

PORTER, M. Vantagem competitiva: Criando e sustentando um desempenho superior. Rio de Janeiro: Campus, 1992

REGINATO, Carlos E R; GRACIOLI, Odacir D. Gerenciamento estratégico da informação por meio da utilização da inteligência competitiva e da gestão do conhecimento- um estudo aplicado à indústria moveleira do RS. São Carlos: Gest. Prod., São Carlos, 2012. 